\title{
Use of the Ottawa Ankle Rules in children: a survey of physicians' practice patterns
}

\author{
Shawn K. Dowling, MD*; Ian Wishart, MD*
}

\section{ABSTRACT}

Introduction: A number of studies have assessed the diagnostic accuracy of the Ottawa Ankle Rules (OAR) in children; however, the role of the OAR in guiding physician radiograph use is unclear.

Objectives: The primary purpose of this study was to determine the extent to which Canadian pediatric emergency physicians report using the OAR. Secondary goals included determining current diagnostic and management strategies for Salter-Harris 1 (SH-1) injuries of the ankle and which fractures physicians deem to be clinically significant.

Methods: A self-administered piloted survey was distributed by mail to 215 Canadian pediatric emergency physicians using a modified Dillman technique. Participants were selected through Pediatric Emergency Research Canada (PERC), a national network of health care professionals with an interest in pediatric emergency medicine research.

Results: Of 209 surveys, 144 were returned, for a response rate of $68.9 \%$. Of those, $87.5 \%$ (126 of 144 ) reported applying the OAR in children to determine the need for radiographs in acute ankle or midfoot injuries. Of those, $65.1 \%$ reported using the OAR always or usually, and $64.5 \%$ (93 of 144) of physicians stated that they believe all ankle fractures are clinically significant. Although physicians report that they most commonly order the radiographs, $36.2 \%$ of participants indicated that radiographs were requisitioned by nurses or other health care providers at their facilities. $\mathrm{SH}-1$ fractures were reported to be most commonly managed by immobilization (83.3\%; 120 of 144), with most patients going on to follow-up with an orthopedic surgeon.

Conclusions: The majority of Canadian pediatric emergency physicians indicate that they use the OAR when assessing children with acute ankle and midfoot injuries. Most physicians believe that all ankle fractures, including $\mathrm{SH}-1$, are clinically significant and have a management preference for immobilization and orthopedic follow-up.

\section{RÉSUMÉ}

Introduction : Un certain nombre d'études ont évalué I'exactitude diagnostique des règles d'Ottawa concernant les blessures à la cheville (Ottawa Ankle Rules ou OAR) chez les enfants; toutefois, le rôle de I'OAR pour guider le médecin dans I'utilisation de radiographies n'est pas clair.

Objectifs : L'objectif premier de cette étude était de déterminer dans quelle mesure les médecins d'urgence pédiatrique canadiens se servent de I'OAR. Les objectifs secondaires comprenaient : établir les stratégies actuelles de diagnostic et de traitement des blessures à la cheville SalterHarris 1 (SH-1), et quelles fractures les médecins considèrent comme cliniquement significatives.

Méthodes : Une enquête pilote autoadministrée a été distribuée par la poste à 215 médecins d'urgence pédiatrique canadiens, utilisant la technique Dillman modifiée. Les participants étaient sélectionnés parmi le Groupe de recherche en urgence pédiatrique du Canada (PERC), un réseau national de professionnels de la santé s'intéressant à la recherche en médecine d'urgence pédiatrique.

Résultats : Des 209 enquêtes, 144 ont été retournées, pour un taux de réponse de 68,9\%. Parmi les répondants, 87,5\% (126 sur 144) ont rapporté appliquer I'OAR chez les enfants pour déterminer la pertinence de radiographies en cas de blessures aiguës de la cheville ou du milieu du pied. Parmi ceux-ci, $65,1 \%$ ont rapporté utiliser I'OAR toujours ou généralement, et $64,5 \%$ (93 sur 144) des médecins ont affirmé que selon eux, les fractures à la cheville sont toutes cliniquement significatives. Même si les médecins disent être ceux qui demandent le plus souvent les radiographies, 36,2\% des participants ont indiqué que dans leur établissement, les infirmières ou autres professionnels de la santé faisaient la demande pour des radiographies. Les fractures $\mathrm{SH}-1$ étaient le plus souvent traitées par l'immobilisation (83,3\%; 120 sur 144); la plupart des patients consultent un chirurgien orthopédique pour le suivi.

From the *Department of Emergency Medicine, Alberta Children's Hospital, University of Calgary, Calgary, AB.

Poster presented at the International Conference of Emergency Medicine, San Francisco, CA, April 3-6, 2008, and at the Annual Meeting of the Canadian Association of Emergency Physicians, Ottawa, ON, June 2-6, 2008.

Correspondence to: Dr. Shawn K. Dowling, Department of Emergency Medicine, University of Calgary, North Hill Centre 32, Unit 1633, 1632-14th Avenue, NW, Calgary, AB T2N 1M7; skdowling@gmail.com.

Submitted June 9, 2010; Revised October 12, 2010; Accepted November 15, 2010. 
Conclusions : La majorité des médecins d'urgence pédiatrique canadiens indiquent qu'ils se servent de I'OAR lorsqu'ils évaluent des enfants ayant des blessures à la cheville et au milieu du pied. La plupart des médecins croient que toutes les fractures de la cheville, y compris les $\mathrm{SH}-1$, sont cliniquement significatives, et ils montrent une préférence de traitement pour l'immobilisation et un suivi en orthopédie.

Keywords: Ottawa Ankle Rules, pediatrics, practice patterns, Salter-Harris fractures
Acute ankle injuries are a common reason for children to present to the emergency department (ED). Although there is a clear role for radiographs, ankle radiographs reveal a fracture in only 12 to $21 \%$ of pediatric cases. ${ }^{1,2}$ Ankle radiographs may be overused in children for a number of reasons, including difficult or inadequate physical examination, patient and/or parental expectations, or fear of missing an injury.3 Unnecessary radiographs expose patients to radiation, as well as increasing wait times and health care expenditures..$^{1,2}$

The Ottawa Ankle Rules (OAR) are a clinical decision instrument derived and validated by Stiell and colleagues ${ }^{4}$ for use in adults with acute ankle and midfoot injuries (Figure 1). The OAR have been found to be $100 \%$ sensitive for ruling out clinically significant fractures. The implementation of the OAR in the adult population has been found to decrease radiograph use, as well as wait time and health care expenditures. ${ }^{4,5}$

Despite the OAR being validated and widely used in adults, their role in the pediatric population (less than
18 years of age) has not been clearly established. There has been ongoing interest in the pediatric literature to validate the OAR in this population. A number of studies. ${ }^{2,3,6-13}$ have examined the OAR and found varying sensitivities, specificities, and impact on radiograph use. The results likely arise for a number of reasons, including the age of the patients enrolled, study design, and definition of clinically significant fractures. A recent systematic review and meta-analysis found that the pooled sensitivity for the OAR in children was $98.5 \%$ (95\% CI 97.3-99.2). ${ }^{14}$ Despite these recent studies, we are unaware of any studies that have assessed pediatric emergency physician (PEP) practice patterns with respect to the use of the OAR in children for acute ankle and midfoot injuries.

The primary purpose of this study was to determine the extent to which Canadian PEPs report using the OAR. Secondary goals included determining current diagnostic and management strategies for SalterHarris 1 (SH-1) injuries of the ankle and what fractures PEPs deem to be clinically significant.

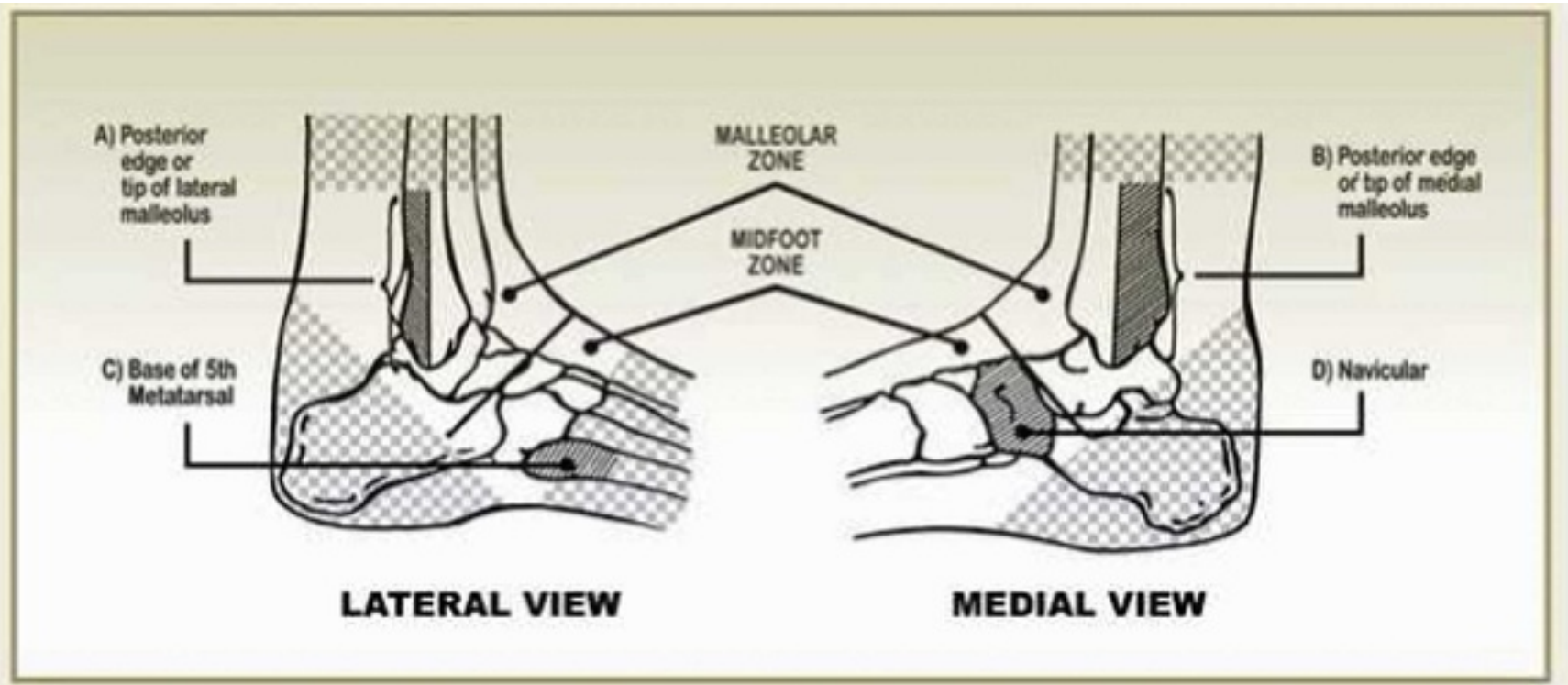

Figure 1. An ankle $x$-ray series is only required if there is any pain in the malleolar zone and any of the following findings: bone tenderness at A), bone tenderness at B), or an inability to bear weight both immediately and in the emergency department (ED). A foot $\mathrm{x}$-ray series is only required if there is any pain in the midfoot zone and any of the following findings: bone tenderness at $\mathrm{C}$ ) or bone tenderness at D), or inability to bear weight both immediately and in the ED. Reproduced with permission from Stiell IG et al. ${ }^{4}$ 


\section{METHODS}

\section{Survey tool}

A self-administered survey was developed and piloted among 20 emergency physicians for face validity and clarity. The survey (Appendix, available online) was then distributed by mail to 215 PEPs across Canada between December 2006 and March 2007. The 215 physicians surveyed represented all physician members of Pediatric Emergency Research Canada (PERC), a network of health care professionals interested in pediatric emergency medicine research.

The survey instrument included a series of questions to capture information on physician demographics and current practices and factors contributing to practice decisions. Multiple-choice questions were used, with additional options for free-form answers where appropriate. Responses to free-form answers were categorized by themes. Any physician who practiced pediatric emergency medicine in Canada was eligible for the study; nonphysicians, unreachable PERC members (e.g., undeliverable mail), and physicians who did not practice pediatric emergency medicine were excluded.

\section{Survey protocol}

The survey was administered using a modified Dillman's Tailored Design Method for mail and Internet surveys. ${ }^{15}$ This methodology uses repeated mailings to maximize survey response rates while preserving the anonymity of the responders. Rather than three mailings interspersed by three reminder cards for nonresponders, only two reminder cards were issued The mail package included a cover letter describing the purpose of the study and indicating that completion of the survey implied consent. The University of Calgary Conjoint Health Research Board approved the study.

\section{Data entry and analysis}

All data were entered into Microsoft Access (2000) and analyzed using $S A S$ version 9.1 (SAS Institute, Cary, $\mathrm{NC)}$ by a trained research assistant. Overall response rates were calculated, and univariable frequencies were determined. To assess any associations between predefined independent factors (years in practice, training, and primary practice) and practice patterns, chi-square tests and $t$-tests were used, with Fisher correction in the case of small cell counts. Categorical data were collapsed into similar categories (e.g., "usually" was collapsed with "always," and "never" was collapsed with "rarely") if cell counts were less than 5.

\section{RESULTS}

\section{Respondents}

Of the 215 physicians surveyed, 6 were excluded based on a priori exclusion criteria; 4 were unreachable because of incorrect addresses, and 2 were allied health providers and therefore not PEPs. This resulted in a sample of 209 PEPs. Of these, 144 completed the survey, for an overall response rate of $68.9 \%$. Of the 144 surveys, 142 were completed in their entirety. Of the two incomplete surveys, each had only two questions unanswered; as a result, all surveys were included in the analysis.

Table 1 provides the baseline characteristics of the study population. The mean number of years in practice was 9.2. Seventy-two percent of respondents described their primary practice as pediatric emergency medicine and $75.7 \%$ practiced full-time emergency medicine.

\section{OAR use}

The frequency of Ottawa Ankle Rules use is provided in Figure 2. The majority of respondents (87.5\%) indicated that they used the OAR when managing acute pediatric ankle or midfoot injuries. Physicians who used the OAR had worked an average of 5.2 years less than those who did not use the rules $(p=0.003)$ and did not consider pediatric emergency medicine their primary practice $(p=0.024)$.

Of those respondents who used the OAR, 65.1\% (95\% CI 58-74) used the ankle portion "usually" or "always," whereas 50\% (95\% CI 41-59) used the foot portion "usually" or "always."

For those respondents who did not routinely use the OAR, 56.4\% preferred to use clinical judgment, $29.8 \%$ felt that age limitations precluded use of the rule, especially in patients under age 5 , and $10.5 \%$ stated that they felt there was inadequate evidence to support the use of the OAR in children.

\section{Diagnoses and management of pediatric ankle injuries}

Participants indicated that the decision to order ankle and foot radiographs was most frequently made by 


\begin{tabular}{|c|c|c|c|}
\hline Characteristic & $\begin{array}{l}\text { All respondents } \\
\quad(N=144)\end{array}$ & Use OAR $(n=126)$ & Do not use OAR $(n=18)$ \\
\hline Years in practice (SD) & $9.24(6.80)$ & $8.58(6.68)$ & $13.73(6.05)$ \\
\hline \multicolumn{4}{|l|}{ Practice, $n(\%)$} \\
\hline Full time & $109(75.7)$ & $97(77.0)$ & $12(66.7)$ \\
\hline \multicolumn{4}{|l|}{ Primary practice, $n(\%)$} \\
\hline Pediatrics & $104(72.2)$ & $95(75.4)$ & $9(50)$ \\
\hline \multicolumn{4}{|l|}{ Training, $n(\%)$} \\
\hline CCFP or CCFP-EM & $12(8.3)$ & $11(8.7)$ & $1(5.6)$ \\
\hline FRCP-EM or ACEP & $13(9.0)$ & $11(8.7)$ & $2(11.1)$ \\
\hline FRCP-PEDS & 48 (33.3) & $41(32.5)$ & 7 (38.9) \\
\hline FRCP-PEDS with & 56 (38.9) & $51(40.5)$ & $5(27.8)$ \\
\hline \multicolumn{4}{|l|}{ PEM } \\
\hline Other & $12(8.3)$ & $12(9.5)$ & $3(16.6)$ \\
\hline
\end{tabular}

physicians (61.8\%), followed by nurses (29.2\%), orthopedic technicians $(4.9 \%)$, and other health care providers $(2.1 \%)$.

Overall, $52.1 \%$ (75 of 144) of participants defined an $\mathrm{SH}-1$ fracture as requiring both joint-line tenderness and swelling with a normal bony radiograph. Of the remaining respondents, $27.7 \%$ (40 of 144) defined an $\mathrm{SH}-1$ fracture as joint-line tenderness and a normal radiograph and $11.1 \%$ (16 of 144 ) indicated that they diagnosed SH-1 only when a radiographic abnormality was seen.

Table 2 outlines the participants' responses to the questions of which fractures are clinically significant; $64.5 \%$ (93 of 144) of PEPs felt that all fractures were of clinical significance.

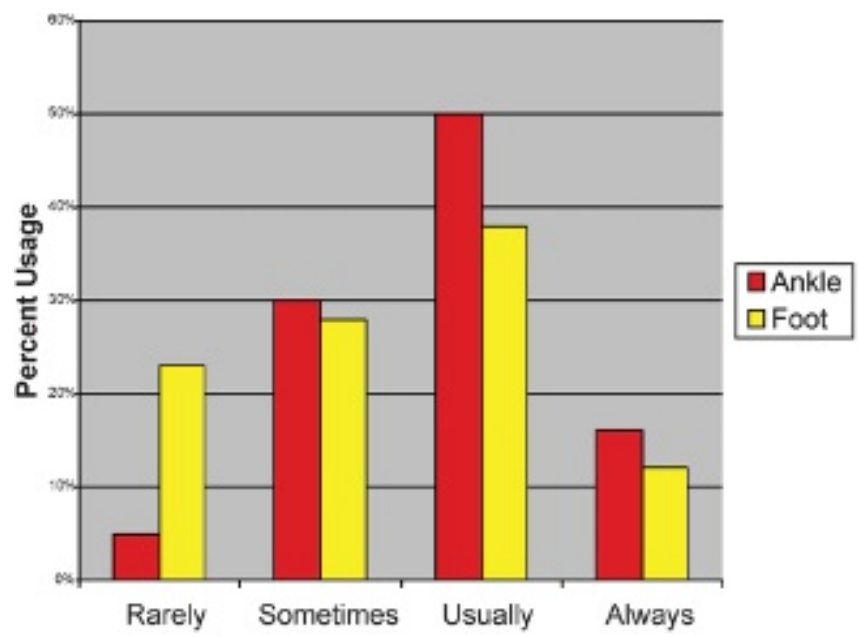

Figure 2. Frequency of use of the Ottawa Ankle Rules in children reported by pediatric emergency physicians.
Information on practice related to immobilization and follow-up is provided in Table 3. The majority of participants $(83.3 \% ; 120$ of 144$)$ indicated that they manage SH-1 fractures with immobilization, and $58.3 \%$ (84 of 144) of these have follow-up arranged with an orthopedic surgeon.

\section{DISCUSSION}

The diagnosis and management of pediatric ankle injuries remain controversial. The OAR have been validated and accepted in adult practice, but until recently, the accuracy of this instrument in children was unclear. A recent systematic review and meta-analysis of 12 studies and over 3,100 patients found a pooled sensitivity of $98.5 \%$ (95\% CI 97.3-99.2) for the OAR in children and a reduction in radiograph use of $24.8 \%$ (Level 2 evidence). ${ }^{14}$ Because of difficulties in examining

\begin{tabular}{|lc|}
$\begin{array}{l}\text { Table 2. Responses to question regarding which ankle/ } \\
\text { midfoot fractures are significant }\end{array}$ \\
\hline Fracture & $n(\%)$ \\
\hline $\begin{array}{l}\text { Avulsions fractures }<3 \mathrm{~mm} \\
\text { Salter-Harris } 1 \text { fracture- } \\
\quad \text { normal radiograph }\end{array}$ & $10(7.1)$ \\
$\begin{array}{l}\text { Salter-Harris } 1 \text { fracture- } \\
\quad \text { abnormal radiograph }\end{array}$ & $12(8.5)$ \\
$\begin{array}{l}\text { Salter-Harris } 2 \text { fracture } \\
\text { (nondisplaced) }\end{array}$ & $20(14.2)$ \\
$\begin{array}{l}\text { Any buckle fracture } \\
\text { All fractures }\end{array}$ & $6(4.3)$ \\
\end{tabular}




\begin{tabular}{lc|}
\hline $\begin{array}{l}\text { Table 3. Participant management of Salter-Harris } \mathbf{1} \text { ankle } \\
\text { fractures }\end{array}$ \\
\hline Management & $n(\%)$ \\
\hline $\begin{array}{l}\text { Immobilize and follow-up in ED } \\
\text { Immobilize and follow-up with family }\end{array}$ & $19(13.2)$ \\
doctor & $17(11.8)$ \\
Immobilize and follow-up with & $84(58.3)$ \\
orthopedic surgeon & $6(6.3)$ \\
Reassure; symptomatic treatment & $15(10.4)$ \\
\hline Other & \\
\hline ED $=$ emergency department.
\end{tabular}

children under 6 years of age and few patients in this subgroup, the authors recommended that the OAR should be used cautiously in this age group. As a result, the use of the OAR is considered an excellent alternative to routine radiography in children $>5$ years of age with blunt trauma to the ankle or midfoot. ${ }^{16}$

Our study indicates that the majority of Canadian PEPs use the OAR when evaluating ankle and foot injuries. Those who used the rules were more likely to have recently completed a residency program and not be primary PEPs. Although most of the participants in our study used the OAR, one-third stated that they use the OAR sometimes, rarely, or never. For PEPs who did not routinely use the OAR, most prefered to use clinical judgment to determine the need for radiography, whereas others indicated a reluctance to use the OAR in preschoolers. In light of the findings of recent studies and the aforementioned meta-analysis, it seems unlikely that "clinical judgment" would supersede the performance of a highly sensitive decision tool such as the OAR. Given the demonstrable reliability of this rule to detect pediatric ankle injuries, the reluctance of a third of physicians to use it may reflect inadequate knowledge translation. The OAR were originally validated in an adult population, and considerable effort has been made to actively disseminate information regarding appropriate use of this rule. The pediatric validation of the rule has required several more years and numerous studies. This slower diffusion of information may have limited knowledge translation to physicians and health care providers.

Establishing consensus on what constitutes a clinically significant pediatric ankle fracture and the optimal management of pediatric ankle injuries is an important clinical question. To our knowledge, this is the first study to assess emergency physician management of pediatric ankle injuries. Our findings suggest that the majority of physicians feel that all ankle fractures are clinically significant in this age group and that immobilization and orthopedic follow-up are the preferred management plan for fractures, including $\mathrm{SH}-1$ injuries. These responses are consistent with the traditional approach to managing SH-1 injuries of the ankle. ${ }^{17}$ More recent literature on this subject suggests that ankle bracing or tubular bandaging of SH-1 ankle injuries results in similar outcomes to plaster immobilization. ${ }^{18}$ There is also increasing evidence that many SH-1 ankle injures do not have demonstrable fractures on magnetic resonance imaging. ${ }^{19,20}$ In light of this recently published data, the results of our study suggest that current management of $\mathrm{SH}-1$ fractures may be more aggressive than required. Given the evolving literature on the diagnosis and management of this common pediatric injury, further clarification of optimal therapeutic intervention is required.

In our study, the majority of participajnts indicated that physicians order the radiographs, but 36.2\% indicated that orthopedic technicians or nurses were primarily responsible for this. A prior study assessed the accuracy of the OAR in children when performed by a nurse. ${ }^{9}$ In this study, the nurses correctly interpreted the OAR in $98.4 \%$ of cases and had $100 \%$ interobserver agreement. In light of current lengthy ED wait times and the increase in nursing protocols allowing for initiation of investigations such as radiographs prior to physician assessment, future studies should further assess the accuracy and impact of nurses and orthopedic technicians' use of the OAR in children.

\section{LIMITATIONS}

This study is limited by its reliance on self-reporting and the inherent recall and other biases of such a design. What physicians claim to do and what their actual clinical practice is may vary. Some survey respondents may have overreported adherence to the OAR if they perceived this to be more professional or acceptable. Although our survey response rate of $68.9 \%$ was impressive, it is possible that those who did not respond chose not to participate because they do not use OAR. As a result, our study participants may represent a skewed sample of the PEP population. The physicians surveyed were all members of a collaborative nationwide pediatric emergency medicine research network. This is a research-based organization based in 
14 teaching and children's hospitals across Canada. Although the participants represent the majority of practicing PEPs in Canada, this group may not reflect practice in community and nonacademic centres, and the generalizablity of the results may be limited because of this.

\section{CONCLUSION}

The majority of Canadian PEPs indicate that they use the OAR when assessing children with acute ankle and midfoot injuries. Most physicians believe that all ankle fractures, including $\mathrm{SH}-1$, are clinically significant and have a management preference for immobilization and orthopedic follow-up. Future studies should focus on knowledge translation of the OAR in the pediatric setting, assessing the accuracy of application of the OAR by allied health care providers, and determining the optimal diagnostic and treatment approaches to $\mathrm{SH}-1$ fractures.

Acknowledgments: We thank the Canadian Association of Emergency Physicians (CAEP) for the research grant that allowed this study to be completed. We also thank Charlie Victorino for his data entry expertise, Shelley Nicholls for her administrative support, and Drs. Eddy Lang and Grant Innes for reviewing the manuscript and providing insightful suggestions.

Competing interests: Funding was provided by a 2007 CAEP research grant.

\section{REFERENCES}

1. Vargish T, Clarke WR, Young RA, Jensen A. The ankle injury-indications for the selective use of x-rays. Injury 1983;14:507-12.

2. Clark KD, Tanner S. Evaluation of the Ottawa ankle rules in children. Pediatr Emerg Care 2003;19:73-8, doi:10.1097/ 00006565-200304000-00003.

3. Boutis K, Komar L, Jaramillo D, et al. Sensitivity of a clinical examination to predict need for radiography in children with ankle injuries: a prospective study. Lancet 2001; 358:2118-21, doi:10.1016/S0140-6736(01)07218-X.

4. Stiell IG, Greenberg GH, McKnight RD, et al. Decision rules for the use of radiography in acute ankle injuries. Refinement and prospective validation. FAMA 1993;269: 1127-32, doi:10.1001/jama.269.9.1127.

5. Anis AH, Stiell IG, Stewart DG, Laupacis A. Costeffectiveness analysis of the Ottawa Ankle Rules. Ann
Emerg Med 1995;26:422-8, doi:10.1016/S0196-0644(95) 70108-7.

6. Al Omar MA, Baldwin GA. Reappraisal of use of $\mathrm{x}$-rays in childhood ankle and midfoot injuries. Emerg Radiol 2002;9: 88-92.

7. Chande VT. Decision rules for roentgenography of children with acute ankle injuries. Arch Pediatr Adolesc Med 1995;149: 255-8.

8. Cuello-Garcia C, Ruiz-Flores A, Ramos-Gomez L, MedinaLopez ME. The Ottawa ankle rules: evaluation in a pediatric emergency setting in Mexico. Anales De Pediatria 2004;60: 454-8, doi: $10.1157 / 13059649$.

9. Karpas A, Hennes H, Walsh-Kelly CM. Utilization of the Ottawa ankle rules by nurses in a pediatric emergency department. Acad Emerg Med 2002;9:130-3, doi:10.1111/ j.1553-2712.2002.tb00229.x.

10. Libetta C, Burke D, Brennan P, Yassa J. Validation of the Ottawa ankle rules in children. 7 Accid Emerg Med 1999;16: $342-4$.

11. McBride KL. Validation of the Ottawa ankle rules. Experience at a community hospital. Can Fam Physician 1997;43:459-65.

12. Plint AC, Bulloch B, Osmond MH, et al. Validation of the Ottawa Ankle Rules in children with ankle injuries. Acad Emerg Med 1999;6:1005-9, doi:10.1111/j.1553-2712.1999. tb01183.x.

13. Dohin B, Lubanziado D. Validation of the Ottawa Ankle Rules for varus ankle trauma in children: A prospective study of 160 cases. 2004. 7 Bone Foint Surg - British Volume 2002; 86(Supp 20).

14. Dowling S, Spooner CH, Liang Y, et al. Accuracy of Ottawa Ankle Rules to exclude fractures of the ankle and midfoot in children: a meta-analysis. Acad Emerg Med 2009;16:277-87. Epub 2009 Feb 2, doi:10.1111/j.1553-2712.2008.00333.x.

15. Dillman DA. Mail \& Internet Surveys: the Tailored Design Method. New York: John Wiley \& Sons; 2000.

16. Runyon MS. Can we safely apply the Ottawa Ankle Rules to children? Acad Emerg Med 2009;16:352-4.

17. Dias LS, Tachidjian MO. Physeal injuries of the ankle in children. Clin Orthop 1978;136:230-3.

18. Gleeson AP, Stuart MJ, Wilson B, Phillips B. Ultrasound assessment and conservative management of inversion injuries of the ankle in children: plaster of Paris versus Tubigrip. 7 Bone foint Surg 1996;78B:484-7.

19. Launay F. Barrau K, Petit P, et al. Ankle injuries without fracture in children. Prospective study with magnetic resonance in 116 patients. Rev Chir Orthop Reparatrice Appar Mot 2008;94:427-33.

20. Boutis K, Willan AR, Babyn PI, et al. A randomized, controlled trial of a removable brace versus casting in children with low-risk ankle fractures. Pediatrics 2007;119: e1256-63, doi:10.1542/peds.2006-2958. 